\title{
Emergence of Interventional Nephrology in the Asia-Pacific Region - A Report from New Zealand
}

\author{
Naveed Ahmed ${ }^{*}, 1$, Angus G. Ritchie ${ }^{2}$, Michael Lam-Po-Tang ${ }^{3}$ and Tushar J. Vachharajani ${ }^{4}$ \\ ${ }^{1}$ North Shore Hospital, Auckland, New Zealand \\ ${ }^{2}$ Concord Repatriation General Hospital, Australia \\ ${ }^{3}$ Middlemore Hospital, Auckland, New Zealand \\ ${ }^{4}$ Department of Nephrology, W.G. (Bill) Hefner Veterans Affairs Medical Center, Salisbury, North Carolina, USA
}

\begin{abstract}
Interventional nephrology is relatively a new field dealing with the procedural aspect of dialysis access. The subspecialty has focused on the nephrologist taking a lead role and learning the procedural skills needed to provide timely care to the end stage renal disease patients on dialysis. The subspecialty has been in existence for over a decade in the United States and is well accepted as a main-stream field. The safety and positive outcomes of nephrologists performing these procedures in the United States are being duplicated across the globe. The growing trend of acceptance of this field is evident in the Asia-Pacific region, which is rapidly embracing this new development. The current report from New Zealand is being presented here in this article.
\end{abstract}

Keywords: Interventional Nephrology, dialysis access, dialysis, peritoneal dialysis, hemodialysis, catheters, stenosis, fistula.

\section{INTRODUCTION}

The field of interventional nephrology emerged in the United States in the mid-1990 primarily to improve the quality of dialysis access care provided to end stage renal disease (ESRD) patients [1-3]. The complexity of issues involved in the management of patients with ESRD often results in suboptimal care, especially that involving dialysis access. The dialysis access has remained a "weak link" in the overall management of ESRD patients and its care often remains fragmented [4]. The end result being an increase in access related morbidity and mortality with significant economic burden to healthcare [5].

The subspecialty of interventional nephrology encompasses basic procedures involved in dialysis access care and includes insertion of tunneled and non-tunneled hemodialysis catheters, peritoneal dialysis catheters, endovascular interventions on arteriovenous fistulae (AVF) and grafts (AVG), ultrasound evaluation of permanent dialysis acces, and ultrasonography of kidneys. Nephrologists also perform various advanced procedures, such as stent placement, coil embolization, portacath placement and renal angiography, when appropriate resources are available. The American Society of Diagnostic and Interventional Nephrology (www.ASDIN.org) was established in 2000 to promote the procedural aspect of nephrology and encourage nephrologists to actively participate and adopt a leadership role for dialysis access care. The nephrologists started performing both diagnostic

*Address correspondence to this author at the North Shore Hospital, Auckland, New Zealand; Tel: +64212463432; Fax: +6494423218;

E-mail: Naveed.Ahmed@waitematadhb.govt.nz and interventional procedures safely and successfully [6]. The society spearheaded in establishing guidelines for training and certification that are widely accepted to credential nephrologist performing various procedures in the United States [7-9].

More than a decade worth of experience from the United States in this new and evolving field has now been widely published in literature. The field of interventional nephrology is being gradually accepted across the world. The current report is a review of the growth of this new field in the Asia-Pacific region and especially in New Zealand.

\section{REPORT FROM NEW ZEALAND}

Around New Zealand, there are 12 Nephrology Units across the different District Health Boards (DHB's). These units vary in size with a prevalence of renal replacement therapy patients as low as 50 and others caring for over 600 patients in 2010 [10]. We report on the difference in practice of interventional nephrology across New Zealand. Currently, the only commonly practiced procedure in most units in New Zealand is the insertion of non-tunneled dialysis catheters. Tunneled haemodialysis catheters are inserted by an interventional nephrologist in $50 \%$ of the units with the remaining units being dependent upon their interventional radiology colleagues. Surgeons predominantly insert peritoneal dialysis (PD) catheters. However, in 1 unit, PD catheters are inserted by radiologists using the Seldinger Technique and by nephrologists using the peritoneoscopic method. In total, only 3 units in New Zealand have nephrologists who insert PD catheters, all using the peritoneoscopic method. Nephrologists in 5 centers in New Zealand routinely perform renal biopsies. In all other units, interventional radiologists perform these. Endovascular 
procedures are currently not performed by nephrologists in New Zealand. All units rely on interventional radiologists either locally or in a tertiary referral institution.

Recently, an online survey was performed to determine the scope of interventional procedures across Australia and New Zealand. The data was published in abstract form in the Australia and New Zealand Special interest group for Interventional Nephrology (ANZSIN) meeting which was held in Auckland New Zealand in August 2012 [11]. The response was received from 13 New Zealand nephrologists practicing in 9 centres including the only tertiary pediatric nephrology service in the country as shown in Table $\mathbf{1}$.

Table 1. Interventional Procedures Performed by Nephrologists or Trainees in 9 New Zealand Centers in Response to a Survey [11]

\begin{tabular}{|l|c|}
\hline \multicolumn{1}{|c|}{ Procedure } & Centers \\
\hline \hline Diagnostic renal ultrasound & 2 \\
\hline Renal biopsy & 4 \\
\hline Simple central venous dialysis catheter insertion & 8 \\
\hline Cuffed central venous dialysis catheter insertion & 5 \\
\hline PD catheter insertion & 3 \\
\hline Fistula ultrasonography & 2 \\
\hline
\end{tabular}

Currently, only 3 units (North Shore Hospital, Waikato Hospital and Middlemore Hospital) have nephrologists trained in interventional nephrology and other interested nephrologists are currently being trained along with renal trainees in these procedural skills.

\section{North Shore Hospital}

As a result of an expansion of services in July 2011, the Renal Unit at North Shore Hospital, Auckland, is managing more than 250 patients on renal replacement therapy, and has successfully developed an interventional nephrology program. Prior to the expansion, most of the dialysis vascular access care was provided at the tertiary care Auckland City Hospital. The expansion of the renal unit required enormous efforts from the hospital director in convincing the Hospital and the District Health Boards for this change. As a result, North Shore Hospital currently has the most comprehensive interventional nephrology services in New Zealand with nephrologists performing insertions of tunnelled hemodialysis and peritoneal dialysis catheters, and real-time ultrasound-guided renal biopsies. North Shore Hospital is also supported by one interventional radiologist for endovascular procedures and one dedicated general surgeon for laparoscopic surgical Tenckhoff catheter insertion needs.

\section{Waikato Hospital}

The Renal Unit at Hamilton is a regional service covering the Central North Island and catering to more than 400 patients on renal replacement therapy and includes two large home based programmes: PD and HD. The interventional nephrology program at Waikato Hospital, Hamilton, Auckland, has been developed predominantly under the impetus from a single nephrologist with specific interest in this field. Tunneled hemodialysis catheters were traditionally placed by interventional radiologist but are now being placed by a nephrologist. Renal biopsies and the insertion of PD catheters are also being performed by a nephrologist

\section{Middlemore Hospital}

Middlemore Hospital, Auckland, is the busiest Nephrology Unit covering a single DHB in New Zealand with over 600 patients on renal replacement therapy. Traditionally, it has been well supported by an excellent team of interventional radiologists who perform all renal biopsies and endovascular procedures. Nephrologists with the occasional support of interventional radiologists generally insert tunneled hemodialysis catheters. In 1999, radiological insertion of PD catheter was introduced as part of a prospective study with comparable outcomes to surgical insertion [12]. In 2009, peritoneoscopic insertion of PD catheters by nephrologists was introduced and a retrospective analysis of outcomes failed to show any significant difference between the different techniques [13, 14]

The development of interventional nephrology in New Zealand has been hampered by a number of factors including the availability and support from other specialists. Another factor contributing to this is the lack of emphasis on teaching procedural skills to advanced trainees in nephrology. According to Royal Australasian College of Physician's (RACP) nephrology curriculum, learning procedures is "highly recommended" but not mandatory for the trainees. Current steps to promote its development have been mostly through the strong links between New Zealand and Australian nephrologists. Nephrologists from both countries with an interest in interventional nephrology organized the first ANZSIN meeting in 2008. This meeting attendance continues to grow and strong associations have been formed with other like-minded international societies such as the American Society of Diagnostic and Interventional Nephrology (ASDIN). Currently, there is a drive from ANZSIN to set parameters for the training and credentialing of nephrologists involved in interventional procedures.

The future of interventional nephrology in New Zealand currently remains promising. Several renal units are looking to reclaim renal biopsies from interventional radiology colleagues as well as considering the introduction of insertion of PD catheter using the peritoneoscopic or the Seldinger technique. We are encouraging our renal trainees to develop the procedural skills. ANZSIN is also planning to develop an Interventional nephrology fellowship program to train interested nephrology fellows in Australia. In view of this change, ANZSIN is collaborating with Vascular and Radiology Australasian College for the credentialing process that will allow nephrologist to achieve certification. The limited training avenues and relatively smaller number of ESRD patients, as well as interventional radiologists unwilling to give up hold on the endovascular procedures, poses unique challenges for the entire spectrum of this field to be widely practiced in New Zealand. 


\section{INTERVENTIONAL NEPHROLOGY IN THE ASIA- PACIFIC REGION}

\section{Australia}

Mantha et al. reported their experience of performing endovascular procedures on 187 dysfunctional AVF and AVG. They performed angiograms, endovascular thrombectomies, stent placement as well as accessory vein ligation. Their clinical success rate was $93 \%$ with an overall complication rate of $5.9 \%$ demonstrating that trained nephrologists could perform effectively and safely in a regional center [15]. The report was accompanied by an editorial highlighting the advent of a new nephrologist in Australia [16]. Since this report, the nephrologists from Australia and New Zealand have formed an interventional society promoting this new field.

\section{India}

The growing chronic kidney disease population, limited number of trained nephrologist and compartmentalized resources in India has not deterred the nephrologists from harvesting this new field for those who can afford the care. Nephrologists in India have been successfully placing Scribner shunt, creating AVF and acute peritoneal dialysis catheters and are slowly transitioning into other procedures necessary to manage patients on dialysis [17]. The benefits of using ultrasound guided central venous catheters in femoral vein was recently reported in a series of 110 patients achieving a success rate of $98.2 \%$ with a significantly lower complication rate of $5.5 \%$ compared to $18.2 \%$ with blind technique [18]. Similar experience with successful placement of 100 tunneled catheters was reported from a single center in Southern India over a 3-year period [19]. The role of interventional nephrologist in placing peritoneal dialysis catheter using Seldinger's technique was also evaluated by the same center highlighting the reduced hospital stay and early initiation of dialysis compared to the common practiced open surgical technique [20]. Interventional nephrologists from a single center dedicated to kidney and urological diseases in the Western State of Gujarat, reported their experience of performing 470 renal arteriograms for atherosclerotic renal artery disease over a 15 -year period. Renal function improved in $79.5 \%$ of patients with stabilization /improvement in blood pressure in 70\% [21].

\section{South Korea and Malaysia}

The radiologists and nephrologists in South Korea perform dialysis access related procedures. A collaborative approach with other specialties such as interventional cardiology and radiology is often an ideal approach for centers with limited resources with ultimate benefit to the patient [3]. Small case series of eight endovascular procedures performed via arterial approach in poorly maturing AVF with a technical and clinical success rate of $87.5 \%$ has been recently reported [22]. Venography for venous mapping before AVF creation has also been reported recently from a radiology group interested in dialysis access care.

The inaugural vascular access symposium was held in Kuala Lumpur, Malaysia in 2010. The second conference concluded recently in October 2012 included a preconference workshop focusing on the role of ultrasonography in the evaluation of AVF and AVG and learning endovascular techniques for failing dialysis vascular access (http://www.vascularmalaysia.org/pdf/final_ann.pdf).

The growing awareness of the importance of dialysis vascular care and the need to develop the field of interventional nephrology in the Asia-Pacific region is evident from the flurry of educational activities that have been organized over the last few years. The concept of team approach is being well received and will help promote further educational and training avenues for future.

\section{CONFLICT OF INTEREST}

The authors confirm that this article content has no conflicts of interest.

\section{ACKNOWLEDGEMENTS}

Declared none.

\section{REFERENCES}

[1] Asif A, Byers P, Vieira CF, Roth D. Developing a comprehensive diagnostic and interventional nephrology program at an academic center. Am J Kidney Dis 2003; 42(2): 229-33.

[2] Vachharajani TJ, Moossavi S, Salman L, et al. Dialysis vascular access management by interventional nephrology programs at University Medical Centers in the United States. Semin Dial 2011; 24(5): 564-9.

[3] Vachharajani TJ, Moossavi S, Salman L, et al. Successful models of interventional nephrology at academic medical centers. Clin J Am Soc Nephrol 5(11): 2130-6.

[4] Asif A, Besarab A, Roy-Chaudhury P, Spergel LM, Ravani P. Interventional nephrology: from episodic to coordinated vascular access care. J Nephrol 2007; 20(4): 399-405.

[5] Vachharajani TJ, Atray NK. Interventional nephrology in a federal hospital: economics of health care. Semin Dial 2006; 19(5): 421-4.

[6] Beathard GA, Litchfield T. Effectiveness and safety of dialysis vascular access procedures performed by interventional nephrologists. Kidney Int 2004; 66(4): 1622-32.

[7] Guidelines for training, certification, and accreditation for hemodialysis vascular access and endovascular procedures. American Society of Diagnostic and Interventional Nephrology. Semin Dial 2003; 16(2): 173-6.

[8] Guidelines for training, certification, and accreditation in renal sonography. Semin Dial 2002; 15(6): 442-4.

[9] Guidelines for training, certification, and accreditation in placement of permanent tunneled and cuffed peritoneal dialysis catheters. Semin Dial 2002; 15(6): 440-2.

[10] Pidgeon G. New Zealand Dialysis and Transplantation Audit 2010. Wellington, National Renal Advisory Board 2012.

[11] Ritchie A, Saunders J, Baer R, May S. A survey of procedural practices of Australian and New Zealand nephrologists. Nephrology 2012; 17: 30.

[12] Voss D, Hawkins S, Poole G, Marshall M. Radiological versus surgical implantation of first catheter for peritoneal dialysis: a randomized non-inferiority trial. Nephrol Dial Transplant 2005; 27(11): 4196-204.

[13] Nguyen T, Lam-Po-Tang M, Beechey D, Marshall M, Voss D. Catheter \& Infection-free survival of different peritoneal dialysis catheter insertion techniques. Nephrology 2012; 17: 62.

[14] Nguyen T, Voss DM, Marshall MR, Beechey D, Lam-Po-Tang M. Post-operative outcomes of three different techniques of peritoneal dialysis catheter insertion. Nephrology 2012; 17: 63.

[15] Mantha M, Killen JP, Baer R, Moffat J. Percutaneous maintenance and salvage of dysfunctional arteriovenous fistulae and grafts by nephrologists in Australia. Nephrology (Carlton) 2011; 16(1): 4652.

[16] Furlong T. The advent of interventional nephrology. Nephrology (Carlton) 2011; 16(1): 45.

[17] Vachharajani TJ, Balasubramaniam J, Abraham G. The current state of interventional nephrology in India. Semin Dial 2012; 25(2): $228-32$. 
[18] Prabhu MV, Juneja D, Gopal PB, et al. Ultrasound-guided femoral dialysis access placement: a single-center randomized trial. Clin J Am Soc Nephrol 2010; 5(2): 235-9.

[19] Sampathkumar K, Ramakrishnan M, Sah AK, Sooraj Y, Mahaldhar A, Ajeshkumar R. Tunneled central venous catheters: Experience from a single center. Indian J Nephrol 2011; 21(2): 107-11.

[20] Sampathkumar K, Mahaldar AR, Sooraj YS, Ramkrishnan M, Ajeshkumar, Ravichandran R. Percutaneous CAPD catheter insertion by a nephrologist versus surgical placement: A comparative study. Ind J Nephrol 2008; 18(1): 5-8.
[21] Hegde U, Rajapurkar M, Gang S, et al. Fifteen years' experience of treating atherosclerotic renal artery stenosis by interventional nephrologists in India. Semin Dial 2012; 25(1): 97-104.

[22] Hong HP, Kim SK. Usefulness of percutaneous intervention with transarterial approach in the salvage of nonmaturing native fistulas status-post transvenous approach failure: transarterial approach in the salvage of nonmaturing native fistulas. Cardiovasc Interv Radiol 2009; 32(6): 1252-6.

(C) Ahmed et al.; Licensee Bentham Open.

This is an open access article licensed under the terms of the Creative Commons Attribution Non-Commercial License (http://creativecommons.org/licenses/by-nc/3.0/) which permits unrestricted, non-commercial use, distribution and reproduction in any medium, provided the work is properly cited. 